DOI: https://doi.org/10.24297/jam.v20i.9028

\title{
Expectation of Rice Pod Production in Iraq by Using Time Series
}

\author{
Gorgees Shaheed Mohammad* \\ University of AL-Qadisiyah, College of Education, Department of Mathematics, IRAQ
}

\begin{abstract}
;
The research aims to shed light on the reality of the production of Rice pods in Iraq during the period of time (1943-2019) and its development with time, then predict the production of Rice pods based on three Models of prediction Models, which are the time regression Model on production, in addition to studying the effect of harvested area on production quantities. Then forecasting the production of the Rice pods according to the Model of the regression of the harvested area on the production, the Autoregression Model, and the integrative moving averages (Box Jenkins Models), and in the end the comparison between the expected values of production through the three Models to know the best Model to represent the time series of production of the Rice pods, through the use of the statistical program (SPSS) , Based on annual secondary data represented by the quantities of Rice pods, and the size of the harvested areas of this material in Iraq for the period from 1945 until 2019 obtained from (Central Statistical Organization, Iraq, 2020)
\end{abstract}

Keyword: Autoregression Model, Rice pods, analysis methods, integrative moving averages, Box Jenkins Models

\section{1-Introduction}

Rice pods are considered one of the main crops and of the group of grains and have special importance among the summer crops. Its cultivation is concentrated in the governorates of the Middle Euphrates, especially in the governorates of Najaf and Qadisiyah. Water, as the abundance of water, plays an important role in the cultivation and production of rice pods in Iraq, and the unavailability of the required quantity of water at the specified time causes the amount of local production to fluctuate (Central Statistical Organization, 2020). In light of the fluctuation of the number of its products locally in the recent period, which may affect the supply of its products locally, and in order to obtain accurate forecasts, this requires a thorough analytical study of statistical models. Models in which to deal with time series and contributed widely in making the Autoregression models and integrative moving averages, which write an acronym ARMA. In order to find a model for predicting the quantities of rice produced in tons, the modern analysis methods are used based on Regression and the Box $\&$ Jenkins methodology because it is one of the most important methods used for forecasting in time series, in order to predict the quantities of rice produced. Therefore, the current study is an applied study due to its application of the concept of modeling time series through actual data. It was obtained from its primary source in forecasting the quantities of future production.

\subsection{Research problem:}

The fluctuation in the amount of domestic production of rice pods is due to the lack of rain and the lack of water coming into Iraq from the sources of the Tigris and Euphrates, Many provinces that grow rice, have been prevented in the past few years, and therefore the cultivation of rice pods have become in need of study and analysis, especially since its economic return It is a large source of livelihood for many farmers, as a result of that the quantities of rice pods in the Iraqi market decreased. Therefore, The research problem lies in Finding the best Model for the time series of production of Rice pods by comparing forecasting Models and Using the optimal Model in forecasting the production of Rice pods in Iraq in the future.

\subsection{Methodology [10],[11],[6],[15][14]:}

Regression Model and (Box \& Jenkins) Methodology will be used to predict the amount of Rice pods produced in Iraq, as it will deal with the series of the annual quantity of Rice Pods and the size of harvested areas and arrive at the appropriate Model that represents this series to determine and reconcile the optimal Model for forecasting in the future, according to the four stages of the Box \& Jenkins methodology, and the analysis of the study data will be based on the statistical program SPSS. 


\subsection{Research Hypotheses :}

The research deals with the following hypotheses

1- There is a statistically significant relationship between production and time that can be used to estimate future forecast of production quantities.

2- There is a statistically significant relationship between harvested area and time that can be used to predict the future harvested area.

3- There is a statistically significant relationship between production and harvested area that can be used to estimate future forecast of production quantities.

4- The proposed Model for Autoregression and complementary moving averages (Box Jenkins Models) is considered the best Model for predicting the production of Rice pods in Iraq.

5- The Autoregression Model and the integrative moving averages are the best Model for predicting the future quantities of production compared to the regression Models.

\section{The development of Rice pods production quantities in Iraq over time[6],[5],[4].}

We will study the regression of the time series for the production of Rice pods in Iraq during the time period (1945 - 2019) as a dependent variable and time as an independent variable. The following table includes the production of Rice pods in Iraq between (1945-2019):

\begin{tabular}{|l|l|l|l|}
\hline Production & The year & Production & The year \\
\hline 329000 & 1945 & 195600 & 1987 \\
\hline 356000 & 1946 & 140635 & 1988 \\
\hline 193000 & 1947 & 231757 & 1989 \\
\hline 350000 & 1948 & 227818 & 1990 \\
\hline 212000 & 1949 & 189103 & 1991 \\
\hline 241000 & 1950 & 237295 & 1992 \\
\hline 84000 & 1951 & 261902 & 1993 \\
\hline 127000 & 1952 & 382865 & 1994 \\
\hline 163000 & 1953 & 312804 & 1995 \\
\hline 180000 & 1954 & 282935 & 1996 \\
\hline 83000 & 1955 & 274255 & 1997 \\
\hline 111000 & 1956 & 389475 & 1998 \\
\hline 154000 & 1957 & 218484 & 1999 \\
\hline 137000 & 1958 & 12398 & 2000 \\
\hline 88000 & 1959 & 4900 & 2001 \\
\hline 118000 & 1960 & 193767 & 2002 \\
\hline 69000 & 1961 & 81315 & 2003 \\
\hline 113000 & 1962 & 250275 & 2004 \\
\hline 143000 & 1963 & 308660 & 2005 \\
\hline 184000 & 1964 & 363338 & 2006 \\
\hline 198000 & 1965 & 392803 & 2007 \\
\hline 182000 & 1966 & 248157 & 2008 \\
\hline
\end{tabular}




\begin{tabular}{|l|l|l|l|}
\hline 308000 & 1967 & 173074 & 2009 \\
\hline 353500 & 1968 & 155829 & 2010 \\
\hline 318300 & 1969 & 235118 & 2011 \\
\hline 180100 & 1970 & 361339 & 2012 \\
\hline 306800 & 1971 & 451849 & 2013 \\
\hline 267800 & 1972 & 403028 & 2014 \\
\hline 175870 & 1973 & 109209 & 2015 \\
\hline 68340 & 1974 & 181320 & 2016 \\
\hline 60540 & 1975 & 265852 & 2017 \\
\hline 163360 & 1976 & 420278 & 2018 \\
\hline 199240 & 1977 & 574705 & 2019 \\
\hline 171950 & 1978 & & \\
\hline 157800 & 1979 & & \\
\hline 166900 & 1980 & & \\
\hline 162200 & 1981 & & \\
\hline 163400 & 1982 & & \\
\hline 110500 & 1983 & & \\
\hline 108700 & 1984 & & \\
\hline 149300 & 1985 & & \\
\hline 141200 & 1986 & & \\
\hline
\end{tabular}

Table 1: production of Rice pods in Iraq between (1945-2019)

We draw the time series for the production of the Rice pods during the studied period of time as:

Rice production in Iraq during the time period (1945-2019)

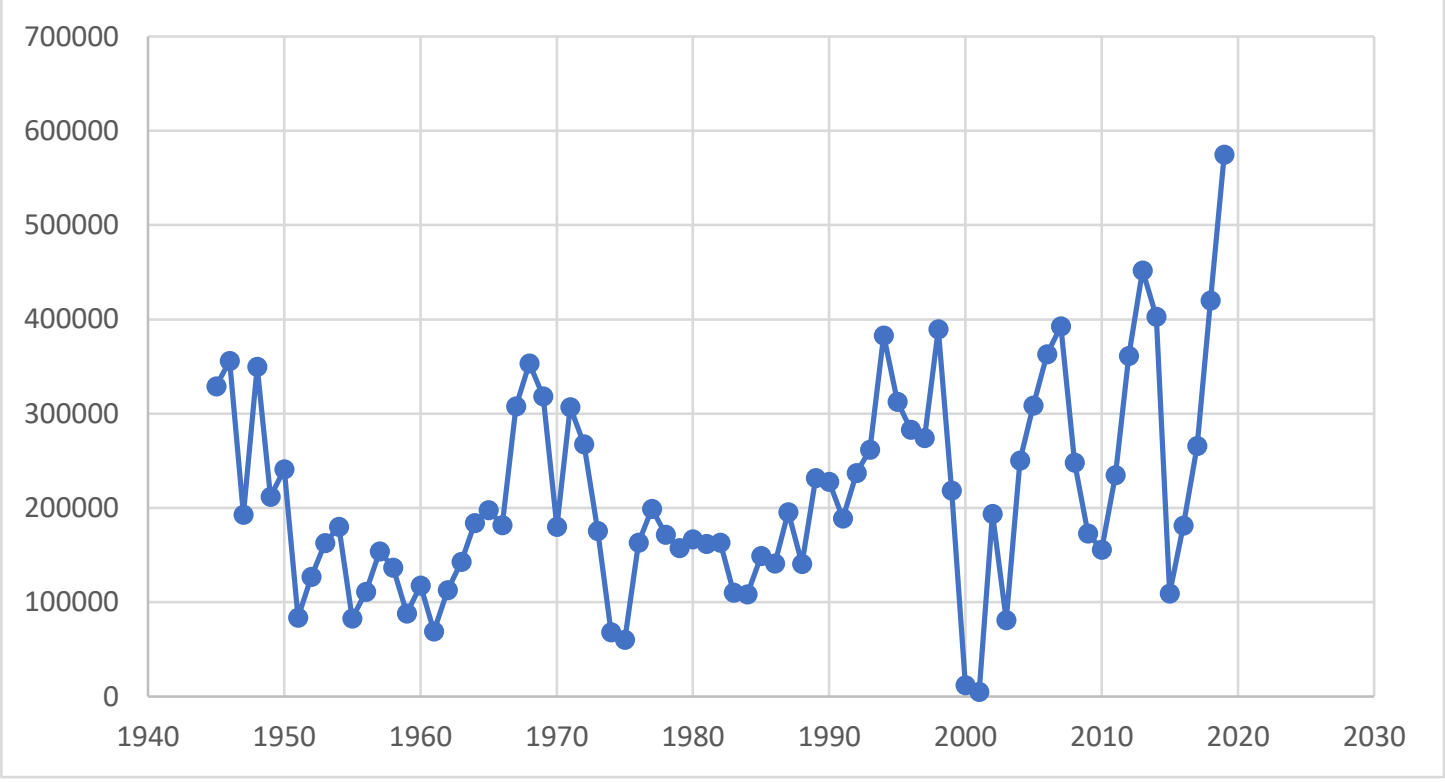

Figure(1)the time series for the production of the Rice pods 
The graph shows that there is a clear fluctuation in the development of Rice pods production over time, especially in the period from 2000 until 2003, but production has increased again in the last three years.

In the study of the evolution of the production of Rice pods material over time, that is, the study of the relationship between the production of Rice pods As a dependent variable and time as an independent variable, by using program SPSS, we obtain the following results:

\section{Model Summary}

\begin{tabular}{|c|c|c|c|}
\hline ModelR & \multicolumn{3}{|c|}{ R SquareAdjusted R SquareStd. Error of the Estimate } \\
\hline 32 & $324^{\mathrm{a}}, 105$ & ,093 & 104389,059 \\
\hline
\end{tabular}

\begin{tabular}{llll} 
ANOVA $^{\mathbf{b}}$ & & \\
\hline \hline Model & Sum of Squaresdf Mean Square & $\mathrm{F}$ & Sig. \\
\hline 1Regression93298020378, 1 & 93298020378, & $8,562,005^{\text {a }}$ \\
Residual & 795486526976 & 7310897075712,0 & \\
Total & 88878454735574 & \\
\hline \hline
\end{tabular}

\section{Coefficient}

\begin{tabular}{|c|c|c|c|c|c|}
\hline \multirow[b]{2}{*}{ Model } & \multicolumn{4}{|c|}{ Unstandardized CoefficientsStandardized Coefficients } & \multirow[b]{2}{*}{ Sig. } \\
\hline & B & Std. Error & Beta & $\mathrm{T}$ & \\
\hline \multicolumn{2}{|c|}{ 1Constant152503,085 } & \multicolumn{2}{|l|}{24350,729} & \multicolumn{2}{|c|}{$6,263,000$} \\
\hline Year & 1629,197 & 556,791 & ,324 & \multicolumn{2}{|c|}{$2,926,005$} \\
\hline
\end{tabular}

a value of the time correlation coefficient was 0.324 , which is a positive and weak correlation. And Upon testing the significance of this coefficient, we found that sig $=0.005$, which is less than the significance level of 0.05 , indicating that the coefficient of correlation between production and time is statistically significant at a significance level of 0.05 .

As for the value of the coefficient of determination $R^{2}$, it reached 0.105 , meaning that approximately $10 \%$ of the changes in the production of Rice pods go back to time, while the remainder of the percentage is due to other factors that were not taken into account.

We also note from the coefficients table that the significant values of the constants of the regression equation, the constant, and the slope are less than 0.05 , that is, they are statistically significant at the level of significance 0.05 , which proves the validity of the first hypothesis. Through the table of analysis of variance, it becomes clear to us that there is a linear relationship between the production of Rice pods and time, through which we can predict the future production of Rice pods, and thus the regression equation between time and production of Rice pods is as follows:

$$
Y=152503,085+1629,197 T
$$


Through this Model, we can predict the production of Rice pods in Iraq during the next five years, so we get the following table:

Table2: predict the production of Rice pods in Iraq for five years

\begin{tabular}{|l|l|l|l|}
\hline Expected production & The year & Expected production & The year \\
\hline 281209,63301 & 2023 & 276322,04259 & 2020 \\
\hline 282838,82982 & 2024 & 277951,23940 & 2021 \\
\hline 284468,02662 & 2025 & 279580,43620 & 2022 \\
\hline
\end{tabular}

3-Evolution of areas harvested with Rice pods in Iraq with time

We will study the development of harvested area production in relation to time in order to predict areas during the next five years to be used in the future prediction of Rice pods when we apply the simple regression equation between the production of Rice pods and the harvested areas. The following table includes the areas harvested with Rice pods in Iraq between (1945-2019)

\begin{tabular}{|l|l|l|l|}
\hline Harvested area & The year & Harvested area & The year \\
\hline 220509.61 & 1945 & 293000 & 1987 \\
\hline 216597.65 & 1946 & 201915 & 1988 \\
\hline 212685.69 & 1947 & 314189 & 1989 \\
\hline 208773.73 & 1948 & 338746 & 1990 \\
\hline 204861.78 & 1949 & 385454 & 1991 \\
\hline 200949.82 & 1950 & 669533 & 1992 \\
\hline 244000 & 1951 & 518607 & 1993 \\
\hline 301000 & 1952 & 651020 & 1994 \\
\hline 378000 & 1953 & 657398 & 1995 \\
\hline 479000 & 1954 & 436580 & 1996 \\
\hline 216000 & 1955 & 450086 & 1997 \\
\hline 280000 & 1956 & 591186 & 1998 \\
\hline 364000 & 1957 & 334468 & 1999 \\
\hline 355000 & 1958 & 16803 & 2000 \\
\hline 235000 & 1959 & 8055 & 2001 \\
\hline 306000 & 1960 & 214585 & 2002 \\
\hline 275000 & 1961 & 115802 & 2003 \\
\hline 244000 & 1962 & 341806 & 2004 \\
\hline 422000 & 1963 & 424250 & 2005 \\
\hline 307000 & 1964 & 495034 & 2006 \\
\hline 329000 & 1965 & 493108 & 2007 \\
\hline 312000 & 1966 & 337408 & 2008 \\
\hline 404000 & 1967 & 219600 & 2009 \\
\hline
\end{tabular}




\begin{tabular}{|l|l|l|l|}
\hline 435100 & 1968 & 191895 & 2010 \\
\hline 423900 & 1969 & 262980 & 2011 \\
\hline 298300 & 1970 & 317884 & 2012 \\
\hline 436300 & 1971 & 383231 & 2013 \\
\hline 376300 & 1972 & 315795 & 2014 \\
\hline 264445 & 1973 & 97560 & 2015 \\
\hline 125660 & 1974 & 150922 & 2016 \\
\hline 119520 & 1975 & 217133 & 2017 \\
\hline 209630 & 1976 & 363912 & 2018 \\
\hline 253940 & 1977 & 510691 & 2019 \\
\hline 218870 & 1978 & & \\
\hline 234800 & 1979 & & \\
\hline 221800 & 1980 & & \\
\hline 229000 & 1981 & & \\
\hline 245000 & 1982 & & \\
\hline 227200 & 1983 & & \\
\hline 181000 & 1984 & & \\
\hline 245200 & 1985 & & \\
\hline 210700 & 1986 & & \\
\hline
\end{tabular}

Table 3: the areas harvested with Rice pods in Iraq between (1945-2019)

The Figure (2) shows that there is a clear fluctuation in the evolution of harvested areas over time, especially in the time period from 2000 to 2003, but they have increased again in the last three years.

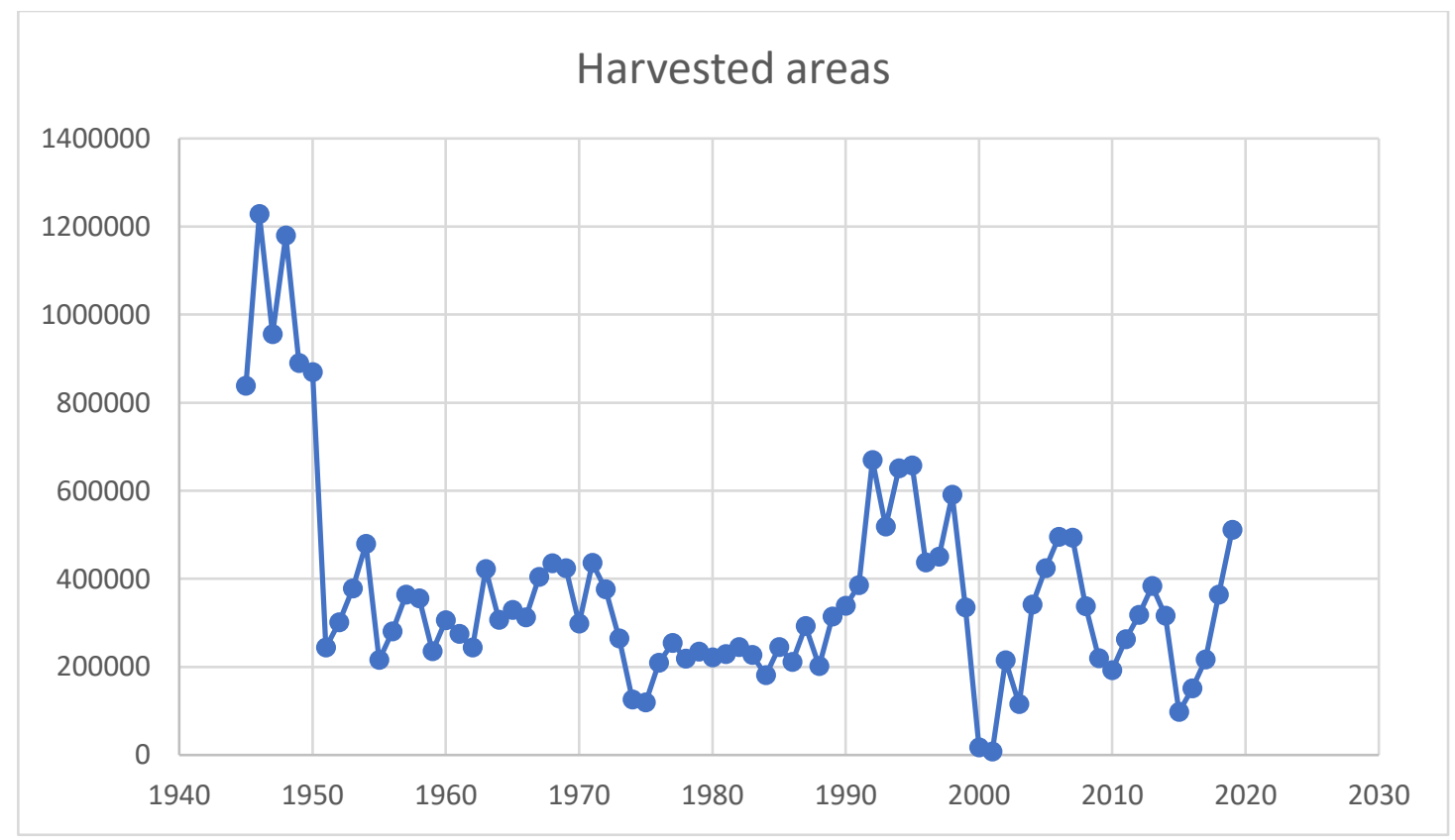

Figure ( 2): The evolution of Harvested areas over time 
The study of the evolution of the harvested area over time, that is, the study of the relationship between the harvested area

As a dependent variable and time as an independent variable, we obtain the following results:

\section{Model Summary}

\begin{tabular}{llll}
\hline \hline ModelR & \multicolumn{2}{l}{ R SquareAdjusted R SquareStd. Error of the Estimate } \\
\hline 1 & $, 368^{\mathrm{a}}, 135$ &, 124 & 216867,493 \\
\hline \hline
\end{tabular}

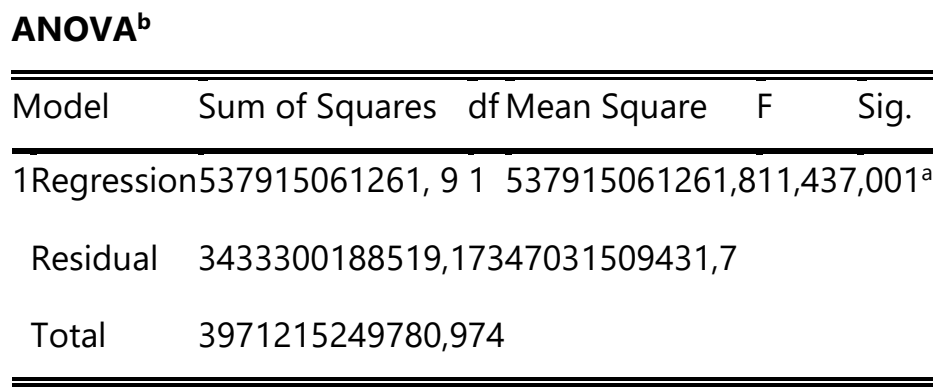

the correlation coefficient value with time was 0.368 , It is an inverse and weak correlation, And when the significance of this coefficient was tested, we found that the value of the sig $=0.001$, It is less than the significance level 0.05 , which indicates the correlation coefficient, Between area harvested and time is statistically significant at a significance level of 0.05 . As for the value of the coefficient of determination, it reached 0.135 , meaning that approximately $13 \%$ of the changes in the harvested area date back to the time, while the remainder of the percentage is due to other factors that were not taken into account. We also note from the coefficients table that the significant values of the constants in the regression equation the constant and the slope were less than 0.05 , meaning that they are statistically significant at the level of significance 0.05 , which proves the validity of the second hypothesis.

We notice through the analysis of variance table it becomes clear to us that there is a linear relationship between the harvested area and time through which we can predict the future harvested area, and thus the regression equation between time and harvested area is as follows:

$$
Y=517818,419-3911,958 T
$$

Through this Model, we can predict the area harvested with raw Rice pods in Iraq during the next five years, and thus we get the following table:

\begin{tabular}{|l|l|l|l|}
\hline The projected harvested area & The year & The Projected harvested area & The year \\
\hline 208773,73382 & 2023 & 220509,60793 & 2020 \\
\hline 204861,77578 & 2024 & 216597,64989 & 2021 \\
\hline 200949,81774 & 2025 & 212685,69185 & 2022 \\
\hline
\end{tabular}

Table 4: predict the area harvested with raw Rice pods in Iraq for five years

\section{Studying the relationship between the production of Rice pods and the harvested areas in Iraq}

The following table includes the dependent variable production and the independent variable the harvested areas with Rice pods in Iraq between the years $(1945,2019)$ : 


\begin{tabular}{|c|c|c|c|c|c|}
\hline Production & Harvested area & The year & Production & Harvested area & The year \\
\hline 329000 & 220509.61 & 1945 & 195600 & 293000 & 1987 \\
\hline 356000 & 216597.65 & 1946 & 140635 & 201915 & 1988 \\
\hline 193000 & 212685.69 & 1947 & 231757 & 314189 & 1989 \\
\hline 350000 & 208773.73 & 1948 & 227818 & 338746 & 1990 \\
\hline 212000 & 204861.78 & 1949 & 189103 & 385454 & 1991 \\
\hline 241000 & 200949.82 & 1950 & 237295 & 669533 & 1992 \\
\hline 84000 & 244000 & 1951 & 261902 & 518607 & 1993 \\
\hline 127000 & 301000 & 1952 & 382865 & 651020 & 1994 \\
\hline 163000 & 378000 & 1953 & 312804 & 657398 & 1995 \\
\hline 180000 & 479000 & 1954 & 282935 & 436580 & 1996 \\
\hline 83000 & 216000 & 1955 & 274255 & 450086 & 1997 \\
\hline 111000 & 280000 & 1956 & 389475 & 591186 & 1998 \\
\hline 154000 & 364000 & 1957 & 218484 & 334468 & 1999 \\
\hline 137000 & 355000 & 1958 & 12398 & 16803 & 2000 \\
\hline 88000 & 235000 & 1959 & 4900 & 8055 & 2001 \\
\hline 118000 & 306000 & 1960 & 193767 & 214585 & 2002 \\
\hline 69000 & 275000 & 1961 & 81315 & 115802 & 2003 \\
\hline 113000 & 244000 & 1962 & 250275 & 341806 & 2004 \\
\hline 143000 & 422000 & 1963 & 308660 & 424250 & 2005 \\
\hline 184000 & 307000 & 1964 & 363338 & 495034 & 2006 \\
\hline 198000 & 329000 & 1965 & 392803 & 493108 & 2007 \\
\hline 182000 & 312000 & 1966 & 248157 & 337408 & 2008 \\
\hline 308000 & 404000 & 1967 & 173074 & 219600 & 2009 \\
\hline 353500 & 435100 & 1968 & 155829 & 191895 & 2010 \\
\hline 318300 & 423900 & 1969 & 235118 & 262980 & 2011 \\
\hline 180100 & 298300 & 1970 & 361339 & 317884 & 2012 \\
\hline 306800 & 436300 & 1971 & 451849 & 383231 & 2013 \\
\hline 267800 & 376300 & 1972 & 403028 & 315795 & 2014 \\
\hline 175870 & 264445 & 1973 & 109209 & 97560 & 2015 \\
\hline 68340 & 125660 & 1974 & 181320 & 150922 & 2016 \\
\hline 60540 & 119520 & 1975 & 265852 & 217133 & 2017 \\
\hline 163360 & 209630 & 1976 & 420278 & 363912 & 2018 \\
\hline 199240 & 253940 & 1977 & 574705 & 510691 & 2019 \\
\hline
\end{tabular}




\begin{tabular}{|l|l|l|l|l|l|}
171950 & 218870 & 1978 & & & \\
\hline 157800 & 234800 & 1979 & & & \\
\hline 166900 & 221800 & 1980 & & & \\
\hline 162200 & 229000 & 1981 & & & \\
\hline 163400 & 245000 & 1982 & & & \\
\hline 110500 & 227200 & 1983 & & & \\
\hline 108700 & 181000 & 1984 & & & \\
\hline 149300 & 245200 & 1985 & & & \\
\hline 141200 & 210700 & 1986 & & & \\
\hline
\end{tabular}

Table 5: the production and the harvested areas with Rice pods in Iraq $(1945,2019)$

Based on the data presented in the previous table, this relationship was analyzed using the SPSS program, the results of the analysis were as follows:

\section{Model Summary}

\begin{tabular}{lll}
\hline \hline ModelR & R SquareAdjusted R Square \\
\hline 1 & $, 555^{\mathrm{a}}, 308$ &, 299 \\
\hline \hline
\end{tabular}

\section{ANOVA}

\begin{tabular}{lcccr}
\hline \hline Model & Sum of Squares & Sum of SquaresMean Square & $\mathrm{F}$ & Sig. \\
\hline 1Regression274051378778,7 & 1 & 274051378778,7 & $32,544,000^{a}$ \\
Residual & 614733168576,3 & 73 & 8421002309,2 & \\
Total & 888784547355,0374 & & \\
\hline \hline
\end{tabular}

\section{Coefficient}

\begin{tabular}{|c|c|c|c|c|c|}
\hline \multirow[b]{2}{*}{ Model } & \multicolumn{2}{|c|}{ Unstandardized Coefficients } & \multicolumn{3}{|c|}{ Standardized Coefficients } \\
\hline & B & Std. Error & Beta & $\mathrm{T}$ & Sig. \\
\hline 1Constant & 117434,471 & 20031,664 & & 5,862 &, 000 \\
\hline Fläche & 263 &, 046 & ,555 & 5,705 & ,000 \\
\hline
\end{tabular}

The coefficient of correlation with time was 0.555 , which is a positive and median relationship. When testing the significance of this coefficient, we found that the value of sig $=0.000$ is less than the significance level of 0.05 , which indicates that the correlation coefficient between the production of the Rice pods and the harvested area is statistically significant at a significance level of 0.05 . As for the value of the coefficient of determination, it amounted to 0.308 , meaning that more than $30 \%$ of the changes in Rice pods production are due to the harvested areas, while the rest of the percentage is due to other factors that were not taken into account. 
We also note from the coefficients table that the significant values of the constants of the constant regression equation and slope were less than 0.05 , meaning that they are statistically significant at a significance level of 0.05 , which proves the validity of the third hypothesis.

Through the analysis table of variance, it becomes clear to us that there is a linear relationship between the Rice production and the harvested area, and this relationship is significant at the level of statistical significance 0.05 , and accordingly, through which we can predict the future production of the Rice, and thus the regression equation between the Rice production and the harvested area is as follows:

$$
Y=117434,471+0,263 X
$$

Through this Model, we can predict the harvested area in Iraq during the next five years, so we get the following table:

\begin{tabular}{|l|l|l|}
\hline Projected harvested area & Expected production & The year \\
\hline 220509,61 & 169970,86 & 2020 \\
\hline 216597,65 & 167950,69 & 2021 \\
\hline 212685,69 & 165930,53 & 2022 \\
\hline 208773,73 & 163910,36 & 2023 \\
\hline 204861,78 & 161890,21 & 2024 \\
\hline 200949,82 & 159870,04 & 2025 \\
\hline
\end{tabular}

Table 6:The predict the Harvested area in Iraq

We notice from the table that the production of Rice is decreasing with the decrease in the harvested area, and this matter is due to the decrease in the harvested area from year to year. In order to compare the two regression Models, which is better, to represent the time series of production of Rice, draw the following Figure:

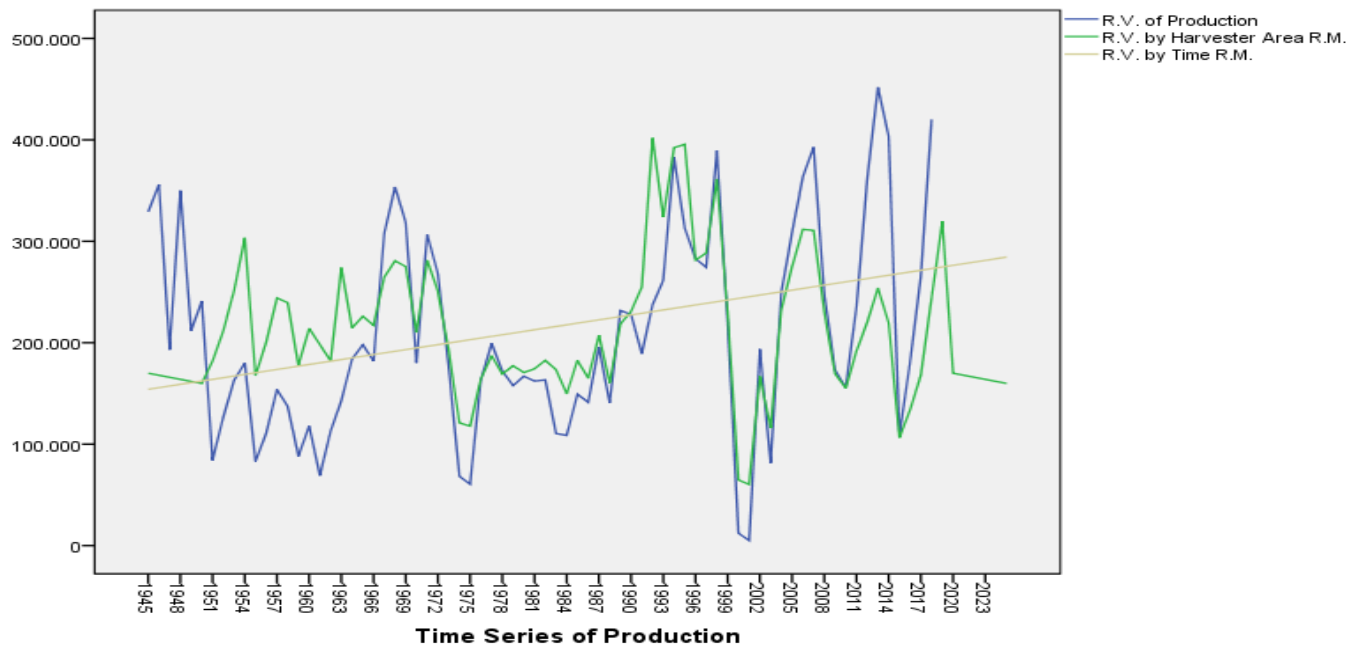

Figure3: time series of production

We note that the harvest area regression Model is better than the time regression Model on production as its data are closer to the real values of production.

\section{Use Autoregression Integrated Moving Average Models (ARIMA) to Predict the production of Rice[13],[15],[14],[11]}

By showing, the Figure (4) of the time series, the Box shape to detect the existence of extreme values in the quantities of production of the Rice for the period studied, and we get the following: 


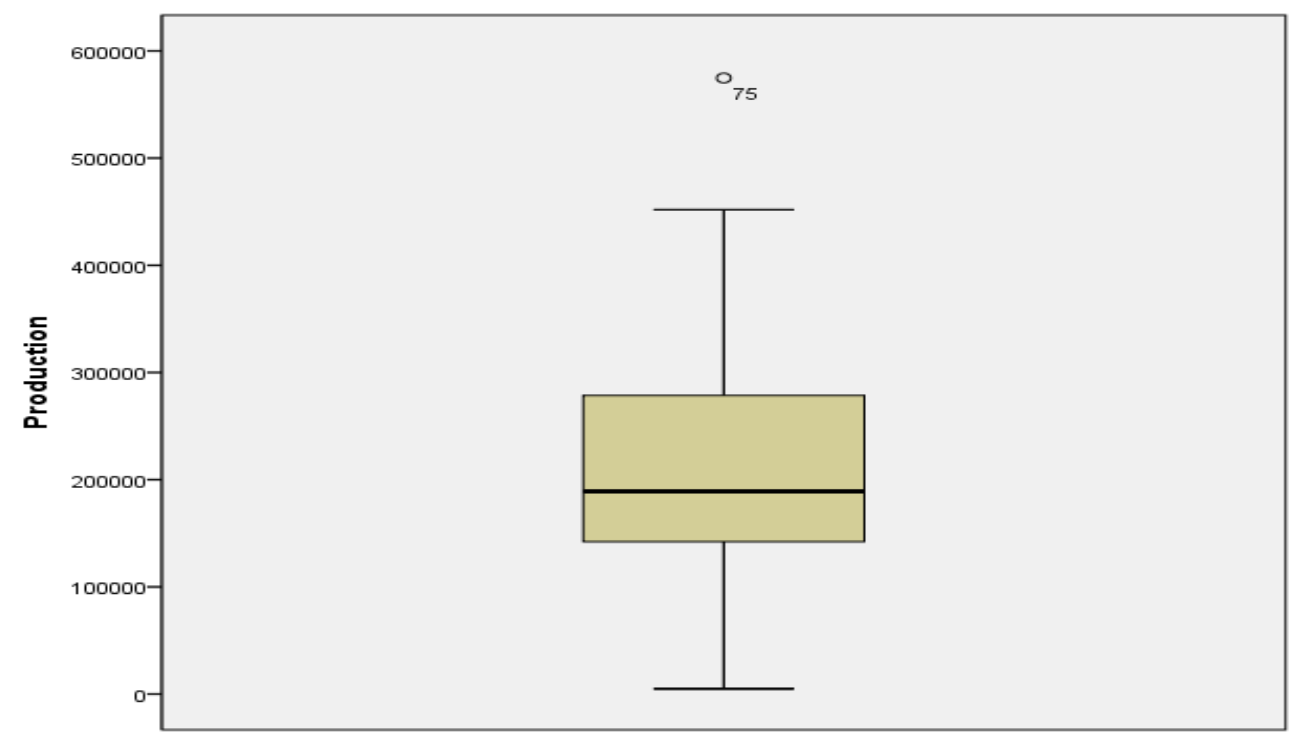

Figure 4: the box plot for time sires

We notice from the Figure the presence of outliers, which is observation number 75 , which corresponds to the year 2019, which is an extreme value, so we delete it and study only the time series within the period (19452018), and then we make a prediction until 2025.

\subsection{Stability analysis[11], [9][6]}

It can be seen from Figure (1) of the time series for the production of the Rice that the series is somewhat stable, and to ensure the stability of the chain or not, we find the autocorrelation coefficients and the partial selfcorrelation coefficients at 16 -time slots:

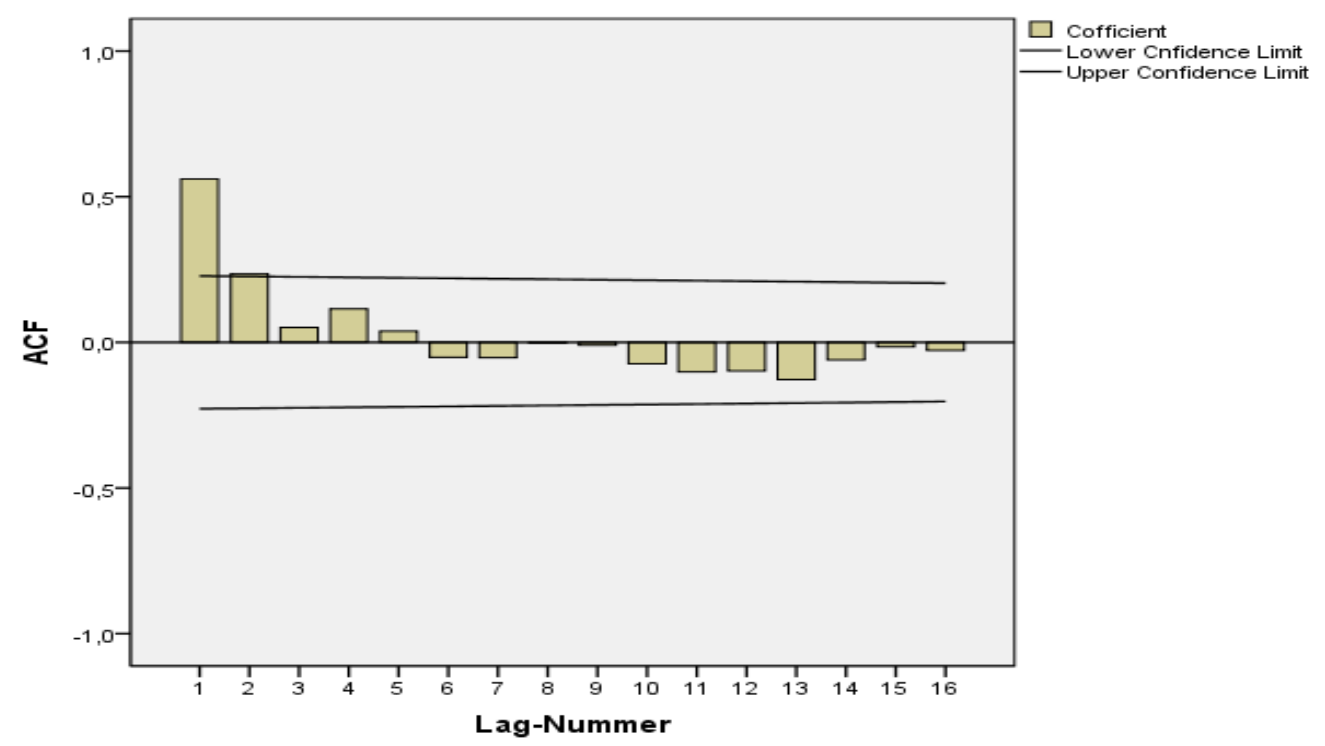

Figure(5) :shows the autocorrelation coefficients for the production of Rice at 16 -time slots

It is clear from the autoregressive form that the time series is stable as the autocorrelation coefficients slope towards zero exponentially with the change of the signal, but there is one significant value, which is the value of the first autocorrelation coefficient.

As for the form of partial self-association, it is as follows: 


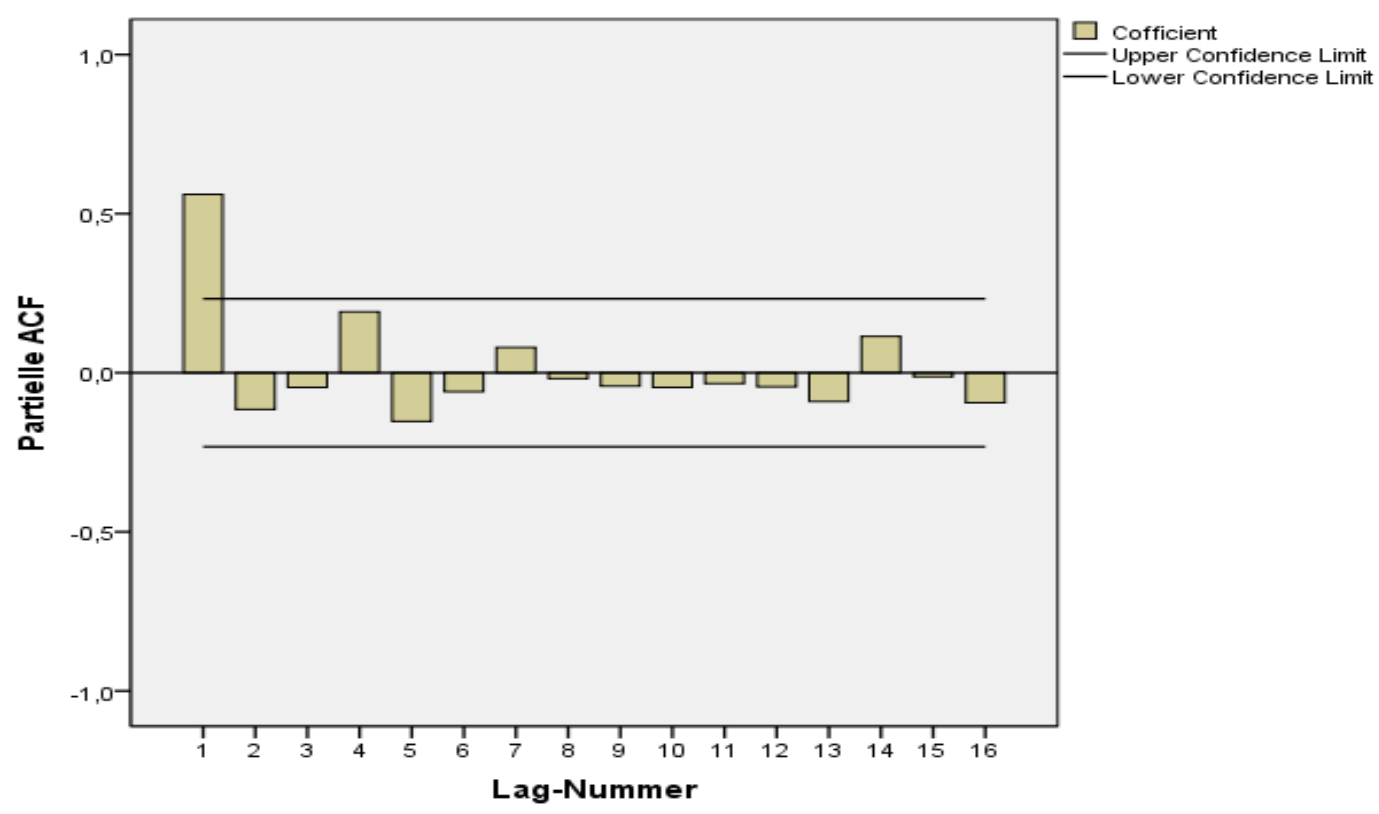

Figure (6): the partial autocorrelation coefficients for production of Rice at 16 time slots

We notice from the form of partial autocorrelation that the autocorrelation coefficients slope exponentially towards zero and that there is one significant value, which is the value of the first partial autocorrelation coefficient.

It is clear to us through the two forms of self-correlation and partial self-correlation that the time series is stable and there is no need to take differences, and it is clear that there is one significant value in the form of selfcorrelation, which is the value of the first self-correlation coefficient, and there is also one significant value in the form of partial self-correlation, which is the value of the coefficient The first partial self-correlation, which suggests to us that the proposed Model for producing Rice pods in Iraq is the following Model: $A R M A(1,1)$ and it's the same Model :ARIMA $(1,0,1)$

\subsection{Get to know the Model[16],[6],[10][11],[18],[19],[20]}

As we said, it appears that the appropriate suggested Model for the time series is $\operatorname{ARMA}(1,1)$

\subsection{Study the proposed Model $\operatorname{ARMA}(1,1)$}

Depending on the two forms of autocorrelation and partial autocorrelation, the Model was determined $\operatorname{ARM} A(1,1)$ As a proposed Model for a time series. By studying this Model, we obtain the following results:

\section{Model-Statistic}

\begin{tabular}{cccc}
\hline \hline \multicolumn{2}{c}{ Statistics } & \multicolumn{2}{c}{ Ljung-Box } \\
\cline { 2 - 4 } ModelR-SquareMAPE & Normal BICStatisticsDfSig. \\
\hline 354 & $83,47722,900$ & 8,235 & 16,942 \\
\hline \hline
\end{tabular}




\section{Parameter ARIMA-Model}

\begin{tabular}{|c|c|c|}
\hline Estimate & St. Error & Sig. \\
\hline \multicolumn{3}{|c|}{$\begin{array}{l}\text { Model Constan 164141,57840055,6634,098,000 } \\
\quad \mathrm{t}\end{array}$} \\
\hline AR Lag 1,442 & 190 & $2,327,023$ \\
\hline MALag 1-,184 & ,208 & $-, 885,379$ \\
\hline
\end{tabular}

The results show that the parameters of the proposed Model are statistically substantial only for the constant and Autoregression ones, as for the moving averages coefficient AM It is not significant, as its significant value reached 0.379, which is greater than 0.05, so we say that the proposed Model is not the best Model, and we study the Model after excluding the moving averages coefficient, which is the Model $\operatorname{ARMA}(1,0)$

\subsection{Study the Model ARMA $(1,0)$.}

By studying this model, we obtain the following results:

\section{Model-Statistics}

\begin{tabular}{cccc}
\hline \hline & \multicolumn{2}{c}{ Statistics } & \multicolumn{3}{c}{ Ljung-Box-Q(18) } \\
\cline { 2 - 4 } ModelR-SquareMAPE NormalBICStatistics & DfSig. \\
\hline 344 & $87,80422,843$ & 9,817 & 17,911 \\
\hline \hline
\end{tabular}

\section{Parameter ARIMA-Model}

\begin{tabular}{rrrr}
\hline \hline Estimate & St. Er & t & Sig. \\
\hline ModelConstant166696,70442974,4133,879,000 \\
AR Lag 1,565 & 100 & $5,631,000$ \\
\hline \hline
\end{tabular}

We note that the coefficients of the Model are statistically significant, which are the onstant and the Autoregression coefficient, the value of $\mathrm{BIC}=22,843$ which is less than the value of $\mathrm{BIC}=22.90$, for the production of the Rice of the proposed Model, meaning that $\operatorname{ARMA}(1,1)$ is the best Model for representing and predicting the time series.

We will now study the two adjacent Models, the higher Model and the lower Model, and since there is no inferior Model, therefore we will only study the higher Model, which is $\operatorname{ARMA}(2,1)$ As the supreme Model $\operatorname{ARMA}(1,0)$

5.6 Study the Model $\operatorname{ARMA}(2,1)$ : We study the indicators and parameters of the top Model, so we get the following tables:

\section{Model-Statistic}

\begin{tabular}{cccc}
\hline \hline & \multicolumn{2}{c}{ Statistics } & \multicolumn{2}{c}{ Ljung-Box-Q(18) } \\
\cline { 2 - 4 } Model R-SquareMAPE NormalBICStatistics Df Sig. \\
\hline 362 & $78,31122,960$ & 8,630 & 15,896 \\
\hline \hline
\end{tabular}




\section{Parameter ARIMA-Model}

\begin{tabular}{|c|c|c|c|}
\hline Estimate & St. Er & $\mathrm{t}$ & Sig. \\
\hline \multicolumn{4}{|c|}{$\begin{array}{l}\text { Model Constan 159966,53334713,0544,608,000 } \\
\quad \mathrm{t}\end{array}$} \\
\hline AR Lag 1,936 & ,588 & 1,591 & 116 \\
\hline Lag 2-,333 & ,321 & $-1,03$ & 5,304 \\
\hline MALag 1,286 & ,614 & ,466 & ,643 \\
\hline
\end{tabular}

We note that all the parameters of the Model are not statistically significant, and the value of $B I C=22,960 \mathrm{It}$ is greater than the value $B I C=22,843$ For the Model $\operatorname{ARMA}(1,0)$, Thus, we can say that the best Model for studying and predicting the time series of Rice production in Iraq is the Autoregression Model of the first degree ARMA $(1,0)$. The following table represents the predicted production values up to 2025 using the optimized Model, ARMA $(0,1)$ :

\begin{tabular}{|l|l|}
\hline Expected production & The year \\
\hline 352889 & 2019 \\
\hline 315358 & 2020 \\
\hline 294706 & 2021 \\
\hline 283593 & 2022 \\
\hline 277874 & 2023 \\
\hline 275202 & 2024 \\
\hline 274254 & 2025 \\
\hline
\end{tabular}

Table(7): represents the predicted production values up to 2025 using the optimized Model, ARMA $(0,1)$

The results showed that we could not predict the proposed Model (the proposed Model is the Model that we proposed depending on the two forms of the self-correlation coefficients and the partial self-correlation), but the ideal Model through which we can predict the Model to production is ARIMA (1, 0), That is, the hypothesis was not fulfilled.

\section{Comparison between regression Models and the Box Jenkins Model for production of Rice}

In this research, we used three Models to predict the production of Rice in Iraq, namely:

1- Time regression Model on production.

2- A Model of regression of harvested area on production.

3- Autoregression Models and integrative moving averages (Box Jenkins Models).

In order to know the best regression Model for the production of Rice, we compare the results of the three Models to see how their results match the actual data of production, by drawing a graph of the expected values according to the three Models.

The following Figure shows the expected values of Rice production: 


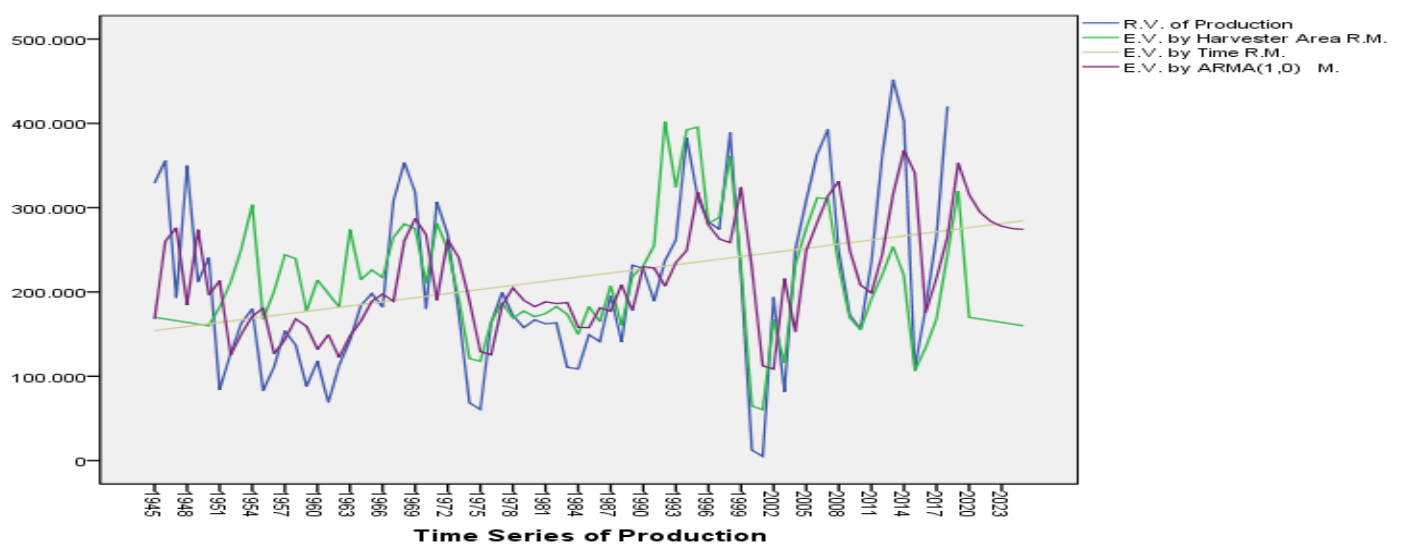

Figure 7:_Comparison between all Models for Rice production

It is evident from the graph that the expected values using the Autoregression Model and the integrative moving averages is the ideal Model for predicting the production of the reed compared to the time regression and harvested area regression Models, because the values expected using this Model of the Autoregression Model and the integrative moving averages are the closest and almost apply to the real values of production during The study period.

Which proves the validity of the fourth hypothesis saying

The Autoregression Model and integrative moving averages are the best Model for predicting future quantities of production compared to regression Models.

\section{Results and Discussion}

The study and analysis of the time series for the production of Rice pods during the time period (1945-2019) showed the following:

1- There is a statistically significant relationship between Rice production and time, which is a direct relationship, but it is weak, meaning that there are other reasons that are more influential on the production of Rice than the time factor.

2- The existence of a statistically significant correlation between the harvested area and time, but this relationship is inverse and weak, meaning that the harvested area decreases with time, in addition to the weakness of this relationship indicates the presence of other factors that affect the harvested area more than the time factor.

3- The presence of a significant correlation between the production of material Rice and the harvested area, and this relationship is positive and average.

4- The factor of harvested area affects more than the effect of the time factor on the production of Rice, and this is evident by comparing the value of the two determination factors. That is, the harvested area explains $30 \%$ of the changes in Rice production.

5- The study showed that the Autoregression Model and the proposed integrative moving averages depending on the two forms of self-correlation and partial self-correlation was not the ideal Model because the parameters of the Model were not significant as required, so we cannot predict the proposed Model.

6- The study showed that the ideal Model for studying the time series for the production of Rice and its future prediction is the Model $\operatorname{ARMA}(0,1)$ Rifle production was predicted with this Model until 2025.

7- A comparison was made between the two regression Models, which is the best to study the series. The Model of rampage of the harvested area on the production of Rice was the best Model compared to the Model of time regression of the production of reeds, and this is evident by comparing the real values of production of reeds and both of the estimated values of production of reeds through the Models of time regression and ramp of harvested area. 
8- A comparison was fully made between the three Models that were predicted for the time series of production, so the Autoregression Model and the integrative moving averages were the best Model compared to the two Models of regression, harvested area and time, where the data of the Autoregression Model and the integrative moving averages were the closest to representing the series data through The period studied is almost applicable to the graph line of the real values of production, compared to the graph of the time regression and the graph of the harvested area regression.

\section{8- Conclusions}

1- The bodies working in the field of producing Rice pods must identify the factors that greatly affect the production of this material, as the apparent fluctuation of the production of Rice pods in Iraq is due to multiple factors that cannot be limited to the factors of time and harvested area, which makes it necessary to determine the factors affecting significantly And finding ways to treat it is of utmost importance.

2 - Conduct a comprehensive survey of the harvested areas, find out the reasons that lead to their decrease, and address these reasons to reduce the decrease in areas, as the increase in areas leads to an increase in the production of material Rice.

3- Providing sufficient support for farmers and institutions working in the field of producing Rice pods so that production becomes a goal sought by many, which leads to increased production and a surplus of this material in Iraq, as well as exporting the surplus, which supplies the state treasury with the foreign pieces necessary for the development process in all Domains.

\section{Reference:}

1. Akaike, H. (1970). "Statistical predictor identification", Ann. Inst. Statist. Math., Vol. 22, pp. 203-217.

2. Akaike, H. (1973)."Maximum Likelihood Identification of Gaussian Autoregressive Moving Average Models", Biometrika, Vol. 60(2), pp. 255-265.

3. Akaike, H. (1979). "ABayesian extension of the minimum AIC procedure of autoregressive Model fitting", Biometrika, Vol. 66(2), pp. 237-242.

4. Anderson, R.I, (1942)."Distribution of the series Analysis Correlation Coeffficient", Ann, Mat.Statistic, Vol 13, pp:113-129.

5. Bisgaard, S. and Kulahci, M., (2011). "Time Series Analysis and Forecasting By Example ", Published by John Wiley \& Sons, Inc., Hoboken, New Jersey.

6. Box, G. and Cox, R., (1964). "An analysis of transformations" ,Journal of the Royal Statistical Society, Series B, Vol.26,No.2, pp.211-252.

7. Box $\square$ G.E.P. and Pierce, D.A., (1970).“Distribution of residual autocorrelations in autoregressiveintegrated moving average time series Models", J. American Statistical Association، 65، 1509-1526.

8. Comwpertwait, P.S.P. \& Metcalf, A.V., (2009). " Introduction to Time Series with R ", Spring, New York.

9. Dickey, D. A. and Fuller, W. A., (1981).“Likelihood Ratio Statistics for Autoregressive Time Series with aUnit Root", Journal of the Econometric Society Vol 49, N (4), pp: 1057-1072.

10. Dritsaki, C. (2015). " Forecasting Real GDP Rate through Econometric Models: An Empirical Study from Greece", Journal of International Business and Economics, Vol. 3, No. 1, pp. 13- 19.

11. Hanke, J. E., \& Wichern, D. W. (2005). " Business Forecasting ", 8th Edition, Pearson, Prentice Hall, New Jersey.

12. Matroushi, S. (2011). "Hybrid computational intelligence systems based on statistical and neural networks methods for time series forecasting: the case of gold pRice", Lincoln University, United Kingdom. 
13. Ljung, G. M. and Box, G. E. P., (1978). "On a measure of lack of fit in time series Models" Biometrika 660 67-72.

14. Miljanovic, M. (2012). "Comparative Analysis of Recurrent and Finite Impulse Response Neural Networks in Time Series Prediction", Indian Journal of Computer Science and Engineering, University of Vienna, Vol 3,No 1, pp:180-191.

15. Mishra, G. C., and Singh, A. (2015). " Application of Box- Jenkins method and Artificial Neural Network procedure for Time series Forecasting of PRices", Statistics in Transition new series, Vol. 16, No. 1, pp. 83- 96.

16. Nuno, C. (1996). "Some Results on the Spectral Analysis of stationary Time Series" Portugal Mathematic, Vol. 53, Fasc. 2.

17. Reinert, G.(2002). " Time Series ", Hilary Term, USA.

18. Schwarz, G. (1978). "Estimating the dimension of a Model ", The Annals of Statistics, Vol. 6, pp. 461-464.

19. Shumway, R. H. and Stoffer, D. S., (2006). "The Time Series Analysis and Its Applications with R Examples", Second Edition, Springer Holden-Day.

20. Siluyele, I., and Jere, J., (2016). "Using Box-Jenkins Models to Forecast Mobile Cellular Subscription", Open Journal of Statistics, No. 6, pp. 303- 309.

Appendix: Abbreviated symbols

Real values of production

Real values by the harvested area regression Model

Real values by The limits regression Model

Estimated values using the time regression Model E.v.by time sires
R.V. of production

R.V. of harvested area R.M.

R.V. by time R.M 